\title{
EDITORIAL
}

La Revista Venezolana de Gerencia me ha honrado altamente al designame su Asesor y más aún al encomendarme el editorial para presentar este número donde el lector encontrará valiosos aportes sobre el cambio institucional que la descentralización implica para los países de América Latina y el Caribe.

El primer articulo que me honro en presentar pertenece a Bernardo Kliksberg. Continuando con sus contribuciones sobre desarrollo social, en este número nos entrega una aplicación valiosisima del concepto de capital social a tres experiencias relevantes en América Latina: la construcción municipal de Vilia EI Salvador, en la periferia de la gran Lima; las Ferias de Consumo en Venezuela y el Presupuesto Participativo en el Municipio de Porto Alegre (Brasil). Todas estas experiencias tienen mucho en común: son procesos de autogestión que se generan a partir de una acumulación institucional que no obedece a políticas inducidas centralmente. En todos estos procesos se ha aprovechado una capacidad institucional extraestatal que se ha venido generando al margen de las políticas oficiales, demostrando asi su extraordinaria vitalidad y el escaso aprovechamiento de tales recursos que las politicas oficiales ostentan. Los procesos de descentralización deberían estar orientados ante todo a aprovechar estos recursos institucionales que se han desarrollado en el seno de la sociedad civil.

En directa relación con los procesos de descentralización que se están adelantando en América Latina, más adelante María Milagros Matheus nos entrega los resultados de una investigación que le permite establecer la ausencia de sistemas eficaces de coordinación entre la nueva realidad politico-administrativa en Aragua y Carabobo (Las Relaciones Intergubemamentales a Raíz de la Reforma del Estado en Venezuela: ¿ Ficción o Realidad?). De esta forma ilustra de manera elocuente cómo en la descentralización de paises que históricamente estuvieron muy centralizados, como Venezuela, el mayor obstáculo para que la gestión pública funcione efectivamente descentralizada, son los sistemas de gestión, que no se han adecuado sino muy parcialmente a los objetivos de la descentralización. Algo similar ocurre en el caso de los municipios, también en Venezuela, según lo demuestra fehacientemente Dionisio Brito (Descentralización y Financiamiento de los Municipios en Venezuela): por un lado se apuesta a la autonomia municipal, pero por otro se mantiene una asignación centralizada de los recursos sin que existan los mecanismos de coordinación que respondan a esta situación.

Otros articulos analizan problemas concretos que debe enfrentar la gestión descentralizada. Neritza Alvarado Chacín (EI Proceso de Ejecución y la Actitud de los Beneficiarios de la estrategia PAMI del Estado Zulia) nos señala dos importantes ausencias en la gestión de la política compensatoria venezolana a partir de una investigación en el Estado Zulia: 1) procedimientos de evaluación de la ejecución del Programa Ampliado Materno Infantil, y 2), directamente relacionado con lo anterior, la opinión y actitud de los beneficiarios respecto a tales servicios. Su pormenorizado análisis, sin embargo, nos brinda los elementos fun- 
damentales sobre los que podrian desarrollarse sistemas de evaluación participativa. El otro tema sería el desarrollo económico territorial. Por un lado Juliana Ferrer, Caterina Clemenza y José L. Vázquez nos entregan los resultados de una investigación sobre encadenamientos productivos que muestra la relación asimétrica que se da entre la industria petrolera del Zulia y el sector metalúrgico y metalmecánico de la región (Estrategias Competitivas: un Aporte a la Búsqueda del Crecimiento y la consolidación del Sector Metalúrgico y Metalmecánico de la Región Zuliana). Por otro lado, Oscar Ermida Uriarte, desde un punto de vista diverso, nos presenta un ensayo donde discute los efectos del descentramiento productivo y la posmodernidad en el mundo laboral (Globalización y Relaciones Laborales). El primero de los dos artículos en mención plantea los problemas de empresarios zulianos frente a la giobalización; el segundo las repercusiones que esta tendencia está ocasionando entre los trabajadores en general. Ermida plantea la necesidad de una legislación laboral internacional ante los problemas emergentes. La fracasada Conferencia de Seattle ha confirmado elocuentemente esta necesidad. Pero ambos tipos de problemas pueden referirse a un tema de la descentralización: el desarrollo económico territorial. Los distintos actores de un territorio dado: gobiemo local, empresarios, microempresarios, trabajadores, organizaciones sociales, organizaciones educativas, etc. podrian concertar estrategias de desarrollo territorial que tomen en cuenta los intereses de todos ellos. ¿Hasta qué punto las políticas de descentralización en vigencia están propiciando esta concertación? ¿Hasta qué punto los propios actores territoriales están aprovechando los resquicios de las politicas centralistas para plantearse estas estrategias?

Finalmente, enfrentar todos estos problemas a través de la descentralización implica nuevos estilos de gerencia en todas las organizaciones involucradas: estatales, sociales, económicas y educativas; la necesidad de efectuar una verdadera revolución en la gerencia en un mundo donde los paradigmas están en crisis pero que a la vez representa oportunidades únicas que hay que aprovechar. Esta es la temática del trabajo presentado por un equipo interdisciplinario de investigadores de distintas organizaciones venezolanas (Comunicación, Gerencia y Futuro).

El conjunto de articulos presentados en este nûmero permite señalar, en suma, la urgente necesidad de adecuar los procesos de descentralización a fin de aprovechar mejor las capacidades colectivas e individuales para situarse estratégicamente ante la globalización. Este esfuerzo no será suficiente, sin embargo, si las organizaciones, por su parte, no adecúan su capacidad de gerencia en función de los nuevos desafíos y no aprovechan las múltiples potencialidades de las nuevas tecnologias de información y comunicación.

\section{Iván Finot*}

* Economista boliviano. Diplomado por el Instituto Internacional de Administración Pública de Francia. Magister en Economía en la Universidad de Los Andes (Colombia). Candidato a Doctor por la Universidad de París. Ha trabajado en varios organismos intemacionales, fue Subsecretario de Planificación de Bolivia en dos oportunidades. Asesor del expresidente Sánchez de Lozada en la elaboración de su polftica de descentralización y participación. Ha sido profesor de las Universidades de los Andes y Javeriana en Bogotá, Católica de Bolivia y Mayor de San Andrés en La Paz. Desde 1993 presta servicios como experto del ILPES. 